\title{
The Status Quo and Development Strategy of "Computer Music Production" Course in Ordinary Normal Colleges and Universities
}

\author{
Yan Zhao \\ School of Music \\ Baicheng Normal University \\ Baicheng, China
}

\begin{abstract}
The course "Computer Music Production" has received more and more attention from colleges and universities in recent years. It is a compulsory course for students majored in music. However with the quick updating of computer in technology, it is necessary to follow the trend of the times and rely on the reality of being an ordinary normal university to unceasingly modify and improve the direction of training, teach students technology in level suitable for their aptitudes so as to meet the demand of society for talents. At present, colleges and universities generally offer computer music production course as a minor course, with less class hours and simplified content, so that students cannot really master and use this technology. Hence in teaching, it is necessary to explain the functional technologies of some software that students may commonly use in work after graduation, so that students can really benefit from the course. This paper makes a research on the development strategy of computer music courses in ordinary normal colleges and universities from perspectives of the status quo, future reform and development direction.
\end{abstract}

Keywords—strategy; serving the society; production

\section{INTRODUCTION}

The "1812 Prelude" [1] (E flat major Prelude "1812", No. $49)$ is an orchestral work created by Tchaikovsky in 1880. It was created to commemorate the event that in $1812 \mathrm{Kutuzov}$ led the Russian people repelling the invasion of Napoleon's army and won the victory of the Russian-French war. The most impressive part in the tune is the real gunfire sound. In some performances, especially outdoor performances, it once was accompanied by real artillery. It is conceivable that how large is the economic investment and danger in playing such music. So, it is urgently needed to create a new technical means to record sound. A "Baba Baa Black Sheep" [2] and an abridged version of "In the Mood" recorded by BBC when visiting Manchester University in 1951 are regarded as the oldest known music recorded by computer in the world. Computer music was introduced into China in about 1990s. From then on, people gradually realized the superiority and advancement of this technology. This technology has also made considerable progress in China and currently has been used in film and television works, media advertisements, literary activities, ceremonial celebrations and other activities. In early 21 st century, colleges and universities all over China set up "Computer Music Production" course, which further accelerated the spreading and development of this technology. But, various problems also appeared gradually.

\section{CURRENT DEVElopment StATUS OF "COMPUTER \\ Music PRODUCTION" IN COLLEGES AND UNIVERSITIES}

Computer music production technology involves in a wide range of content. Therefore in teaching this course, it is needed to teach many contents such as music creation, music editing, multi-track recording and sound mixing [3] based on music theory, harmony, composition, common knowledge of computer, orchestration and other disciplines. It is relatively complex. So, it is necessary help students getting a solid theoretical foundation and having sufficient technical practice in order to make improvement in all aspects. Moreover, the scope of its application also covers a comprehensive field from multimedia teaching in primary and secondary schools to professional music production. Therefore in college education, different teaching content should be provided for students in different employment directions.

The "Computer Music Production" course in specified music colleges and universities should treat the "Computer Music Production" course as a key course to teach and train students so as to enable students to master a solid music production and editing skills. Over an investigation on Jilin University of Arts and Shenyang Conservatory of Music and other professional colleges and universities, it is known that in setting of training program of music theoretical courses, computer music production course is treated as an improving course in musicology theory direction and an optional professional course in performance direction. This course is provided for one semester or one academic year. In such a short period of time, it is relatively difficult to master this relatively complicated and cumbersome technique. In the training program setting, computer music production course should be offered for two years from in the first semester of the sophomore year and it should be taught and assessed as a key course. 
For "Computer Music Production" course in music school of ordinary colleges and universities, it is expected to formulate teaching program and goals based on the characteristics that the future employment market of students is music teacher in primary and secondary schools. After investigating the music schools in various colleges and universities in Jilin Province, it is found that the current teaching goal still focuses on professional music production and editing, equivalent to the teaching goal of computer music production in professional music colleges and universities. This course is often offered only in the next semester of junior year is an optional professional course. This highlights the problems and contradictions: It is difficult to complete such professional teaching content and technical training in such a short semester; moreover, the basic level of students in music schools of ordinary colleges and universities is generally low, which further determines that the setting of the course will not be that helpful for employment of students in the future. In order to deal with such phenomena, we must treat them objectively. It is not to say that ordinary colleges and universities should stop setting up computer music production courses, but they must carry out a drastic reform.

\section{RESEARCH ON DEVELOPMENT DIRECTION OF COMPUTER MUSIC PRODUCTION IN ORDINARY NORMAL COLLEGES AND UNIVERSITIES}

Music education should be provided on the basis of real conditions of the unit and be formulated with a music education program that can serve the society and the local place. Music school in normal college and university should have a computer music training scheme distinguished from that of professional music college and university and its education direction shall be suitable for the development of the college and university and the local place. With respect to normal colleges and universities, students will mainly engage in primary and secondary school music teachers in the future. Therefore, they should mainly train students' basic skills in music score composition and master the methods of audio editing.

Only after being proficiency in music score composition skills can they show students music score example in a more standardized way in the future teaching and further master common knowledge of music theory to more comprehensive and normalized extent. In the teaching of music teachers in primary and middle schools, another important work is the arrangement of literary and artistic activities. Mastering the methods of audio editing can help students to better complete the editing and processing of music in arranging literary and artistic activities in the future and better assist in their teaching work.

In terms of teaching objectives, it is necessary to make clear that the employment direction of student in the future is teacher in primary and secondary schools. Hence, this course should firstly emphasize on the goal to get students master music score A in a normative and proficient way so that they can teach common knowledge of music more accurately in the music teaching in primary and middle schools. For example, it is available to teach software such as "Composer
Master", "over ture4.0", "Yale Simple Music Score", etc. Those APPs can all be found in Chinese, which can reduce the difficulty for students to learn the software. It is both practical and easy to understand. In addition, these three APPs can make simple MIDI music, which enriches the field of use.

It is necessary to get students master simple music editing techniques, such as audio editing, rising-falling tone and simple recording technology. In the music teaching of primary and middle schools, music teachers are also responsible for the arrangement of literary and artistic activities, so mastering these techniques is very helpful for them to arrange such cultural activities. For example, software such as "Adobe Audition", "Pro tools", "Cubase", "Sonar", etc., are also available in Chinese version. Wherein, the Audition's audio editing and recording functions are very powerful and practical. One can easily complete the processing of audios by using this software. Other software is suitable for producing music [4].

It is also necessary to teach students in accordance with their aptitudes. In music school of ordinary colleges and universities, students' basic levels are different. For students with poor foundations, it's $\mathrm{OK}$ to get them master the normative production of numbered musical notation and music score and be proficiency in producing such notation. For students with good foundations, they can be trained and instructed in relatively professional way.

\section{RESEARCH ON TEACHING CONTENT OF COMPUTER Music PRODUCTION IN ORDINARY NORMAL COLLEGES AND UNIVERSITIES}

Computer music covers a wide range of content and has a clear application prospect. For ordinary normal colleges and universities, it is necessary to determine such teaching content according to the employment direction of graduates. At present, the music teaching content in colleges and universities is mainly about "production". But for graduates of music majors in ordinary normal colleges and universities, this "production" technology will not help much in the future employment. First of all, most graduates of music majors in ordinary normal colleges and universities are going to serve as music teachers in primary and secondary schools. For them, the most commonly used skill is Standard spectrum and staff spectrum teaching. Secondly, in major festivals or school activities, they may be responsible for arranging the literary and artistic programs. Thereby, "production" does not help them. Whereas in their arrangement of literary and artistic programs, it is urgently needed to master audio editing, recording, sound mixing and other technical skills.

\section{A. Teaching of Music Notation}

In the teaching of music major in normal colleges and universities, the most basic and most important part of computer music production courses is to let students master the ability to proficiently produce and edit numbered music notation and staves. Because in daily teaching of primary and secondary school music teachers, what they mainly teach is common knowledge of basic music theory and music 
notation. So, it is extremely essential to use software to realize normative demonstration and teaching by virtue of modern teaching media. In addition for some music majored graduates having weak music foundations, they may also use such software to demonstrate and produce simple music accompaniment. Such software is the most reliable auxiliary means for teaching. Over an investigation and interview with graduates of ordinary normal colleges and universities in the past five years, it is verified that it is important to be proficient in producing numbered music notation and staves. In their teaching, it is available to insert normative example of music notations into a PPT to make the teaching content more intuitive and easy to understand.

\section{B. Teaching of Audio Editing}

Audio editing is a method to conduct editing, sound mixing and other processing on audio by using relevant software. For primary and secondary school music teachers, mastering the basic techniques of audio editing is particularly important when arranging dances, reading accompanied with music and sitcoms in literary and artistic activities. Over the investigation, it is found that a considerable number of graduates do not master this technology. In need of conduct audio editing, they also need to seek others for help or ask music production agency to edit at cost. In fact, audio editing technology is not complicated, but it is not involved that much in professional music teaching in colleges and universities. Therefore in future teaching of music colleges and universities, it is necessary to teach and practice this technology to a large extent so that graduates can easily complete the audio editing task rather than having to ask others for help so as to provide a computer music production course really beneficial to students.

\section{Teaching of Audio Effect Processing}

In the daily music teaching of primary and secondary schools, many songs require for teacher's accompaniment. However for students majored in music in ordinary normal colleges and universities, their piano performance and accompaniment ability are different and quite a few students can hardly perform accompaniment tasks. This will bring great difficulty to their music teaching in primary and secondary schools in the future. Here, two solutions are recommended as follows: (1) teach students how to use simple accompaniment software. For example, "band in the box", "over true", etc., have the characteristics of simple use, fast production and obvious effect and can fully satisfy the accompaniment demand of music teaching in primary and middle schools. Moreover, demonstrating the teaching content on the multimedia screen by virtue of software may make students more interested in the course and further improve their enthusiasm for learning. (2) Teach students how to use software to "filter" or transpose a song. For example, "Audition", "pro tools", etc., can be used to process the audio of an original song, filter out the original singing or change the mode of the original accompaniment audio. Instead of teacher's accompaniment performance, this way may not only reduce the teaching burden but also increase the enthusiasm of students to participate in and further obtain a good teaching effect. In addition, it is necessary to pay attention to sound image [5] processing technology. A reasonable use of sound image processing technology may improve the surrounding effect of audio, giving students an "immersive" feeling. For example in the movie "Wolf Warriors 2", there are scenes with both visual and audio 3D effects; it seems that a really bullet flying toward us and we can also hear the rush flying of bullet. It is because of the use of sound image processing technology. For music activities in primary and secondary schools, sound image processing technology is mainly used to provide accompaniment for reading and the scene play. Reasonable sound image processing may provide a more realistic and more appealing accompaniment effect.

\section{Teaching of Recording Technology}

In the past, few music courses involve recording technology. While today, everyone can record video and live and it becomes more and more important to beautify sound. Therefore in future teaching, it is necessary to pay attention to the teaching and practice of recording technology. The teaching of recording can no longer be limited to recording studios and expensive equipment any more, but explore and teach the use of ordinary computers and microphones and achieving simple and practical effect by virtue of software. It is because not every graduate may encounter recording problems and have a lot of money to spend on recording. Thereby, it is necessary for teachers to teach students some simple and practical recording techniques to facilitate their use in future work. At present, there are a lot of competitions on reading accompanied with music. During the preliminary round, it is basically required to mail a sample of the recordings. In many literary and artistic activities, the singing part of a program may be recorded in early stage in order to obtain and guarantee the sound effects of the live scene, which highlights the importance of recording technology. In addition, the key points of teaching and practice are as follows: (1) technology for noise reduction of audio clips [6]. As graduates cannot find recording studios for recording at any time after they work, it is easy to produce various types of noise by recording with ordinary computers and peripheral equipment. Therefore, it is necessary to make a lot of analysis on the types of noise and make targeted noise reduction processing. (2) Teaching of delay effect. Only after being processed in various delay effects, can the recorded audio sounds more pleasant. We may often hear some ambiguous or relatively "dry" audio sounds. It's boring to listen to pure "dry sound"; while the audio being integrated with over much "wet sound" may also sound ambiguous. So, it is very important to proficiently apply delay effect to process the recorded audio. (3) Audio quality processing technology. Currently, there are many hardware and software for sound processing. It is aimed to making more appealing sound by adding various effects to modify it. Therefore, it is needed to constantly look for more audio quality processing methods and techniques, so that graduates can access to more audio quality processing methods in order to meet the demand of the society. 


\section{CONCLUSION}

Computer music production has already been not a strange course in music major of ordinary normal colleges and universities. It is necessary to constantly perfect the training program and improve the practical operation and technical ability of teachers in order to teach students more practical and more advanced knowledge. As a music major in ordinary normal colleges and universities, rather than aiming as high as that in professional music colleges and universities, it is necessary to understand the future employment orientation of students and formulate a training program really beneficial to students' development based on the characteristics of the school so that students can really benefit from it, better serve the society and seek for sound development of themselves.

\section{REFERENCES}

[1] Tchaikovsky. "TCHAIKOVSKY". Hunan Literature and Art Publishing House. 2001.06.

[2] Iza Trapani. "Charlesbridge". 2001.07.

[3] Zhao Yangguang. Practical Manual on Sound Post-Processing by Adobe Audition. Publishing House of Electronics Industry. 2012.07. (in Chinese)

[4] Xue Dongwei. "Cubase Pro9 Practical Technical Guidance". China Radio Film \& TV Press. 2018.07. (in Chinese)

[5] Wang Wenyan. "Sound Image Technology and Audio and Video Production". Publishing House of Electronics Industry. 2016.06. (in Chinese)

[6] Dong Zong. "Professional and Music Production Theory and Practice - Introduction and Application of Pro Tools". Publishing House of Electronics Industry. 2008.4. (in Chinese) 